\title{
Quantitative Analysis of Seven Triazine Herbicides by On-Line Micellar Electrokinetic Chromatography-Electrospray Ionization Mass Spectrometry
}

\author{
Seong Ho Kang, ${ }^{\dagger}$ Dae-Ho Shin, ${ }^{\ddagger}$ and Yoon-Seok Chang ${ }^{*}$ \\ School of Emironmental Science and Engineering. Pohang Universitv of Science and Technologv. Pohang 790-784, Korea \\ ${ }^{\dagger}$ Department of Chemistry, Chonbuk National Lniversity. Jeonju 561-756, Korea \\ Received March 28, 2003
}

\begin{abstract}
This paper presents a successful demonstration of the on-line coupling of MEKC (micellar electrokinetic chromatography) to ESIMS (electrospray ionization mass spectrometry) for the quantitative analy sis of seven $s$-triazine herbicides. The on-line MEKC-ESIMS was used to deternmine the structure of CE-separated peaks of seven triazine herbicides. The mixture of triazine herbicides was separated in a $20 \mathrm{ml} /$ sodium borate buffer (pH 8.5) containing $15 \mathrm{~m} /$ sodium dodecylsulfate (SDS) by using a bare fused-silica capillary. Electrospray ionization mass spectrometer was operated in the positive-ion mode when the mass spectra of seven triazine herbicides were observed from each peak, and the solution of water-methanol-formic acid $(50 / 49 / 1 \mathrm{v} / \mathrm{N} / \mathrm{v})$ was used as a sheath liquid. The effects of SDS concentration the run buffer $\mathrm{pH}$, and the electric field on the separation of seven s-triazine herbicides were investigated. The MEKC-ESIMS detection showed 5 to 10 times higher sensitivity compared to the MEKC-UV detection. In addition it did not need any pretreatment step.
\end{abstract}

Key Words : Triazines, On-line MEKC-ESIMS

\section{Introduction}

Herbicides are important as diverse ervironmental and agricultural species because $s$-triazines are widely used as herbicide in many parts of the world. Because of the complexity of the samples. and because of the mixtures and the low concentrations of compounds present in them. the separation methods of high efficiency unique selectivity. and high sensitivity have been required. The separation techniques of capillary electrophoresis (CE) provide highresolution and high-efficiency analyses of complex samples. Capillary zone electrophoresis (CZE) most frequently used in the CE separation modes is useful in charged species via their charge-to-size ratios. However. CZE is not useful in the separation of neutral and same charged compounds. In the case of neutral and/or same charge species. the addition of ionic surfactant can separate them. ${ }^{.}$The CE separation mode is referred to as micellar electrokinetic chromatography' (MEKC), which is based on the partitioning of the solutes between the run buffer and the micelles to serve as pseudostationary phase. - In particular. sodium dodecylsulfate (SDS) has been successfully used for the various water-soluble analytes in the MEKC mode.

In a report by Forte et al., some triazine herbicides were separated by CZE-indirect UV detection method with mixed water-methanol background electrolytes under the acidic $\mathrm{pH}^{3}{ }^{3}$ Schunitt $e t$ al. also reported that the dependence of buffer $\mathrm{pH}$ on the electrophoretic mobility of chloro-. hydroxy-, methoxy - and thiomethyl-s-triazines ${ }^{4}$ The detection

\footnotetext{
Corresponding author. Tel: $+82-54-279-2281 ;$ Fax: $+82-54-279-$ 8299; E-mail: yschangía postech ac.kr

tPresent address: Korea Basic Science Institute, Seoul Branch, Seoul 136-701, Korea
}

limits for most $s$-triazines were observed to be around 50 $\mathrm{ppb}$. In another report concerning MEKC with in situ charged micelles. Cai and El Rassi employed this novel concept to the separation of three s-triazine herbicides. namely. prometon, prometryn. and propazine. ${ }^{5}$ This MEKC mode reported that high separation efficiency was obtained over a wide range, and that the detection limit of the herbicides was in the range of 18-52 fmol using UV detection. Recently various non-aqueous $\mathrm{CE}$ have also been tried to analyze the triazines.

Because of the low detection limit. high specificity. and more importantly. the structural information. mass spectrometry has been demonstrated as one of the most ideal techniques for detection for gas chromatography (GC) and liquid chromatography (LC). The coupling of highperformance liquid chromatography (HPLC) with mass spectrometer is more difficult than that of $G C$ with mass spectrometer (MS) regarding interface. In the beginning. continuous flow fast atom bombardment (FAB) has been successfully coupled with CE. ${ }^{9-13}$ However the development of electrospray ionization (ESI) source makes the coupling of HPLC and CE much easier and simpler. ${ }^{14.15}$ Compared with $F A B$. ESI has the advantage of operating at atmosphere. and the hydrodynamic flow does not occur because of the vacuum in capillary separation. Therefore. CE-ESIMS techuique can be a promising tool for the high separation efficiency of $\mathrm{CE}$ functions and the high sensitivity of mass spectrometry:

In this study we present a successful demonstration of the on-line coupling of MEKC to ESIMS for the quantitative analysis of seven s-triazines herbicides. The MEKC-ESIMS detection showed 5 to 10 times higher sensitivity compared to the MEKC-UV detection. In addition. it did not need any pretreatment step. This methodology is expected to be a 
valuable tool for the analysis and separation of low concentration pollutants with high sensitivity and simplicity.

\section{Experimental Section}

Reagents. A mixture of triazine herbicides standard (ametryn, atrazine, prometon, prometryn, propazine, simazine, and terbutryn) was obtained from Supleco (Bellefonte. PA. USA). Sudan 1ll, sodium tetra borate, boric acid, and sodium dodecylsulfate (SDS) were purchased from Sigma (St. Louis, MO, USA). Methanol was HPLC grade from FisherScientific (Fair Lawn, NJ, USA). Water was purified with an ultra-pure water system from Millipore (Milford. MA. USA). Deionized water ( $18 \mathrm{M} \Omega$ ) was used for preparation of the sample and buffer solution. 0.I $M$ Sodium hydroxide was prepared for rinsing the capillary, and all solutions were filtered with a $0.45-\mu \mathrm{m}$ Millipak 40 filter (Bedford. MA. USA) followed by degassing before use.

MEKC: UV measurement. All MEKC analyses with UV detection were carried out using a Beckman P/ACE $5000 \mathrm{CE}$ system (Beckman, Fullerton, CA. USA) equipped with a multiwavelength UV absorbance detector. The capillary was a bare fused-silica capillary (Polymicro Technologies, AZ. USA) with the length of $57 \mathrm{~cm}$ total length $\times 50 \mu \mathrm{m}$ l.D. $(50$ $\mathrm{cm}$ to the detector). Samples were introduced with low pressure $\left(0.5\right.$ p.s.i. $\left.-3.4 \times 10^{3} \mathrm{~Pa}\right)$ for $2 \mathrm{~s}$ at the anodic end of the capillary. The run buffer was a $20 \mathrm{~m} M$ sodium borate buffer ( $\mathrm{pH}$ 8.5) containing 0-50 $\mathrm{mM}$ SDS, and the applied voltage was $+5 \cdots+20 \mathrm{kV}$. Electrophoresis was monitored at $2 / 4 \mathrm{~nm}$, and the temperature of capillary was maintained at $20{ }^{\circ} \mathrm{C}$. The Beckman System Gold software (version 8.10) was used for the system control, data collection, and data analysis. To avoid adsorption, the capillary was rinsed with $0.1 M$ sodium hydroxide for $4 \mathrm{~min}$, and then rinsed with water and running buffer for $3 \mathrm{~min}$, respectively. Methanol and sudan III were used as the electroosmotic flow (EOF) marker and the micelle marker, respectively.

On-line MEKC-ESIMS. For on-line coupling to the ESIMS, an ATI Unicam Model 300 Crystal CE system (Boston, MA. USA) was employed. The CE capillary was a bare fused-silica capillary with dimension of $130 \mathrm{~cm}$ length $\times 50 \mu \mathrm{m}$ l.D. $\times 365 \mu \mathrm{m}$ O.D. The run buffer was $20 \mathrm{mM}$ sodium borate buffer ( $\mathrm{pH} 8.5$ ) containing $15 \mathrm{mM}$ SDS. The applied voltage was $+30 \mathrm{kV}$. The sample was introduced hydrodynamically at $300 \mathrm{mbar}\left(-30 \times 10^{3} \mathrm{~Pa}\right)$ for $6 \mathrm{~s}$.

A Quattro II mass spectrometer (Micromass, Manchester, UK) was equipped with Crystal 300 CE for CE-MS interfacing. There are three types of interfaces for CE-MS: coaxial sheath-flow, liquid junction, and sheathless. In the present study, the coaxial sheath-flow interface for MEKCESI/MS was used. The run buffer of MEKC was mixed with a sheath liquid solution at probe tip, and then was nebulized by $N_{2}$ gas. The sheath liquid solution was prepared as a mixture of water-methanol-formic acid (50/49/I $\mathrm{V} / \mathrm{V} / \mathrm{v})$ and delivered to the probe tip at $10 \mu \mathrm{L} / \mathrm{min}$ by a Harvard Apparatus 22 syringe pump (South Natick, MA, USA). Nebulising gas was flowed at $0.5 \mathrm{~L} / \mathrm{min}$, and the source temperature was maintained at $80^{\circ} \mathrm{C}$ to aid desolvation of droplets. In the positive ESI mode, a $+4 \mathrm{kV}$ potential was applied to the probe tip. Therefore, when the high voltage of MEKC mode was maintained at $-30 \mathrm{kV}$, the overall potential across the capillary was about $+26 \mathrm{kV}$. Jotal selected ion current electropherograms were obtained from selected ion monitoring (SIM) mode with 0.2 dwell time and $0.05 \mathrm{~m} / \mathrm{z}$ span.

\section{Results and Discussion}

MEKC: UV measurement. Seven $s$-triazine herbicides with their cortesponding structures, molecular weights, and selected ion monitoring (SIM) are summarized in Table 1. For MEKC-UV separation of $s$-triazines, a bare fused-silica capillary was fielded with run buffer containing $20 \mathrm{mM}$ borate buffer ( $\mathrm{pH} 8.5$ ) and $15 \mathrm{mMSDS}$. Typical MEKC-UV electropherogram of the seven s-triazine herbicides is shown in Figure 1. In general, as the $\mathrm{pH}$ of run buffer increased, the electroosmotic flow (EOF) and the analytes were eluted faster. $\mathrm{pH} .{ }^{16}$ However, in the basic region, the migration time of seven s-triazines was increased according to the increasing $\mathrm{pH}$ (Figure 2). It is inferred that the run buffer $\mathrm{pH}$ has a significant effect on EOF in CZE mode because it changes the zeta potential. However, the EOF in MEKC mode has little effect on the $\mathrm{pH}$ above 8.5 . The MEKC is based on the partitioning of solutes between micelles and the run buffer. Triazine molecules distribute themselves between the buffer and micelles, and the amount of time they spend in the micelles is proportional to their hydrophobicity. In this MEKC experiment, as the run buffer $\mathrm{pH}$ increased, the hydrophobicity increased, and the migration time of triazine was eluted slower than the lower $\mathrm{pH}$. In particular, at $\mathrm{pH} 9.5$ or above, the determination of triazines was possible because each peak of triazines was separated into two peaks. The phenomenon may be caused by hydroxytriazine metabolites as anion at a high $\mathrm{pH}$ of around 9.5. Therefore, considering the resolution and migration time of the s-triazines, we selected the $\mathrm{pH} 8.5$ as the run buffer $\mathrm{pH}$. The dependence of

Table 1. Seven $s$-lriarine herbicides with corresponding structure and molecular weights

$\begin{array}{lllll} & & & \\ \end{array}$

"WW: Molecular weight 


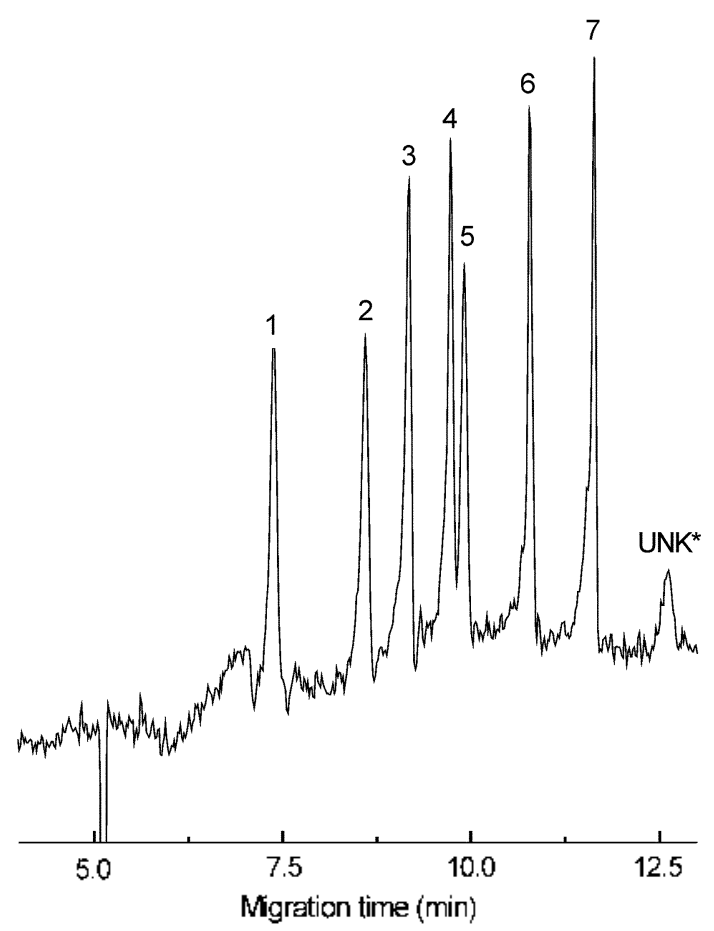

Figure 1. MLKC-UV separation of seven $s$-triazine herbicides. MEKC conditions: run butficr. $15 \mathrm{~mm} / \mathrm{SDS}$ and $20 \mathrm{~mm} / \mathrm{sodium}$ borate buller $(\mathrm{pH} 8.5)$; capillary. $57 \mathrm{~cm}$ total length. $50 \mu \mathrm{m} \mathrm{I.D)..}$ and $365,4 \mathrm{~m} 0.1$ ). lenglh to the detector $50 \mathrm{~cm}$; hydrodsnamic injection. $2 \mathrm{~s}$ at 0.5 p.s.i.: applied voltage. $-15 \mathrm{kV}$ at $20^{\circ} \mathrm{C} ; \mathrm{llV}$ detection at $214 \mathrm{~nm}$. * [ndicates: $1=$ simazine. $2=$ atrazine. $3=$ prometon. $4=$ ametryn. $5=$ propazine. $6=$ prometryn, and $7=$ terbutryn. Sample concentration: $10 \mathrm{ppm}$.

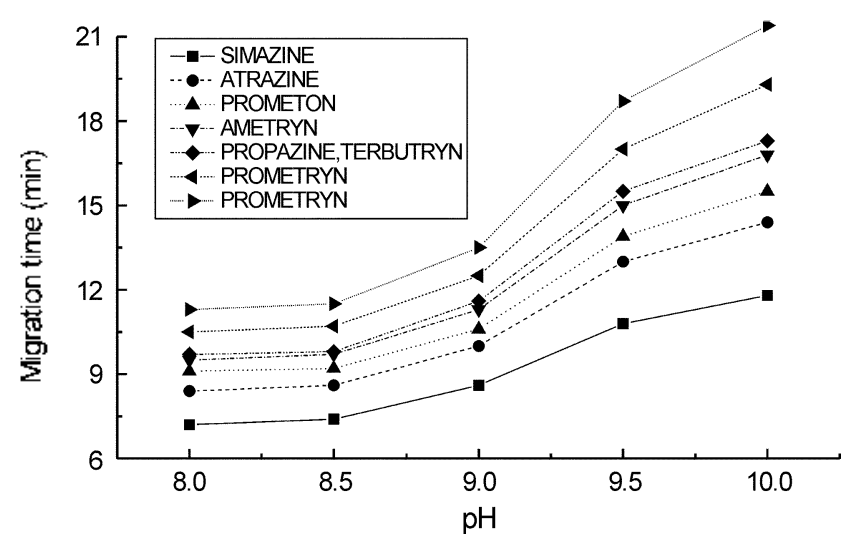

Figure 2. F.lfect of $\mathrm{pH}$ on elution time and order of seven s-triarine herbicides in the Ml:KC-L; V. Ml:KC conditions were the same as in ligure 1 except the pH of run bufter.

the SDS concentration on electrophoretic mobility was investigated at $\mathrm{pH} 8.5$ (Figure 3). The migration times of triazines were increased as the SDS concentration was increased. This effect results from the increased interaction of between SDS and triazines. The separation efficiency was increased with increasing SDS concentration because of more complete association with SDS. However, above 25 $\mathrm{m} M$ SDS, the resolution of ametryn and propazine (peaks 4 and 5 in Figure 1) was decreased. Considering the migration

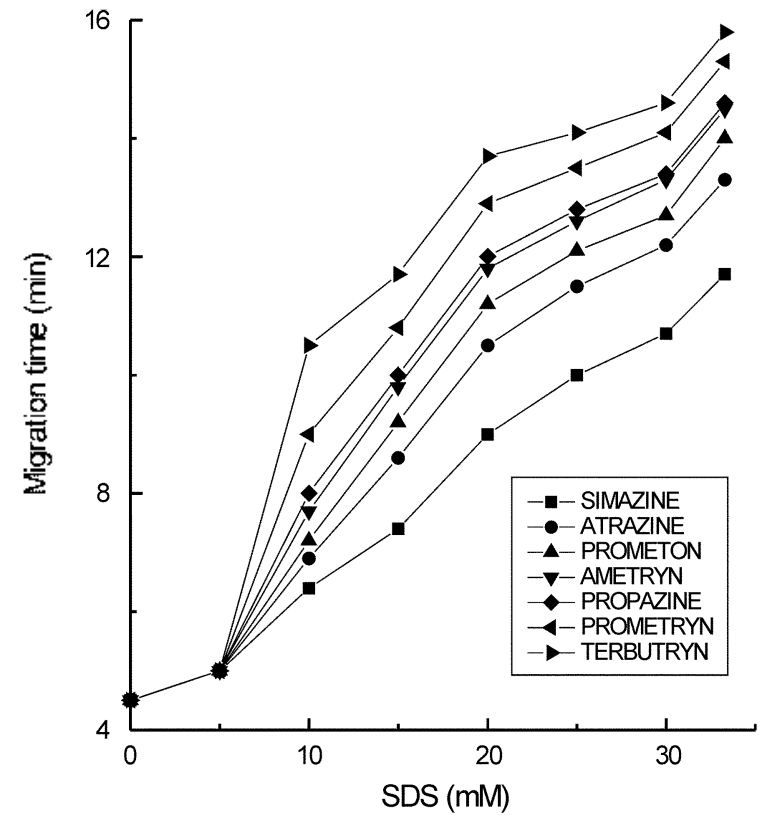

Figure 3. Effect of SDS concentration on clution time and order of seven s-lriazine herbicides in the MFKC-llV. MFKC conditions were the same as in Figure 1 except the concenIration of SIJS.

time and the resolution of seven s-triazines, the optimum separation was observed at $15 \mathrm{~m} M$ SDS. The applied voltage affects the migration time and theoretical plates as well as the resolution. As expected, when the applied voltage was increased from $+5 \mathrm{kV}$ to $-20 \mathrm{kV}$, the migration time became shorter. Even though higher voltage can produce more theoretical plates and shorter migration time, it also causes greater Joule heating ${ }^{17.18}$ and peak broadening. Therefore, we decided the applied voltage to be $+15 \mathrm{kV}$, and all of the seven $s$-triazine herbicides could be analyzed within $12 \mathrm{~min}$ under the MEKC-UV conditions.

On-line coupling of MEKC with EISMS. In the MEKCESIMS experiments, the MEKC separation conditions including the capillary dimensions, run buffer, effective separation distance, SDS concentration, and electric field across the capillary were identical to those employed in MEKC-UV studies at $\mathrm{pH}$ 8.5. Previous studies in which separation of triazines were only performed using CZE and MEKC separation modes..$^{3.519}$ In the present work, MEKC was chosen as the separation technique for MEKC.ESl because of the good separation efficiency for seven $s$ triazines. Even though the ammonium acetate buffer and CHES buffer were well known as a good run buffer for its high volatility, sodium borate buffer was also suitable for MEKC-ESIMS operation. The poor volatility of borate buffer often blocks the orifice of the ESl interface and further contaminates the ion source, which results in reducing the sensitivity. Make-up solution (sheath liquid) performs two functions: one is to enrich the EOF to a suitable level for ESI operation, and the other is to contact between the CE eluent and the ESl probe tip electrically. Therefore, the length between the fused-silica capillary and sheath tube is critical to the sensitivity and stability of C.E/ 


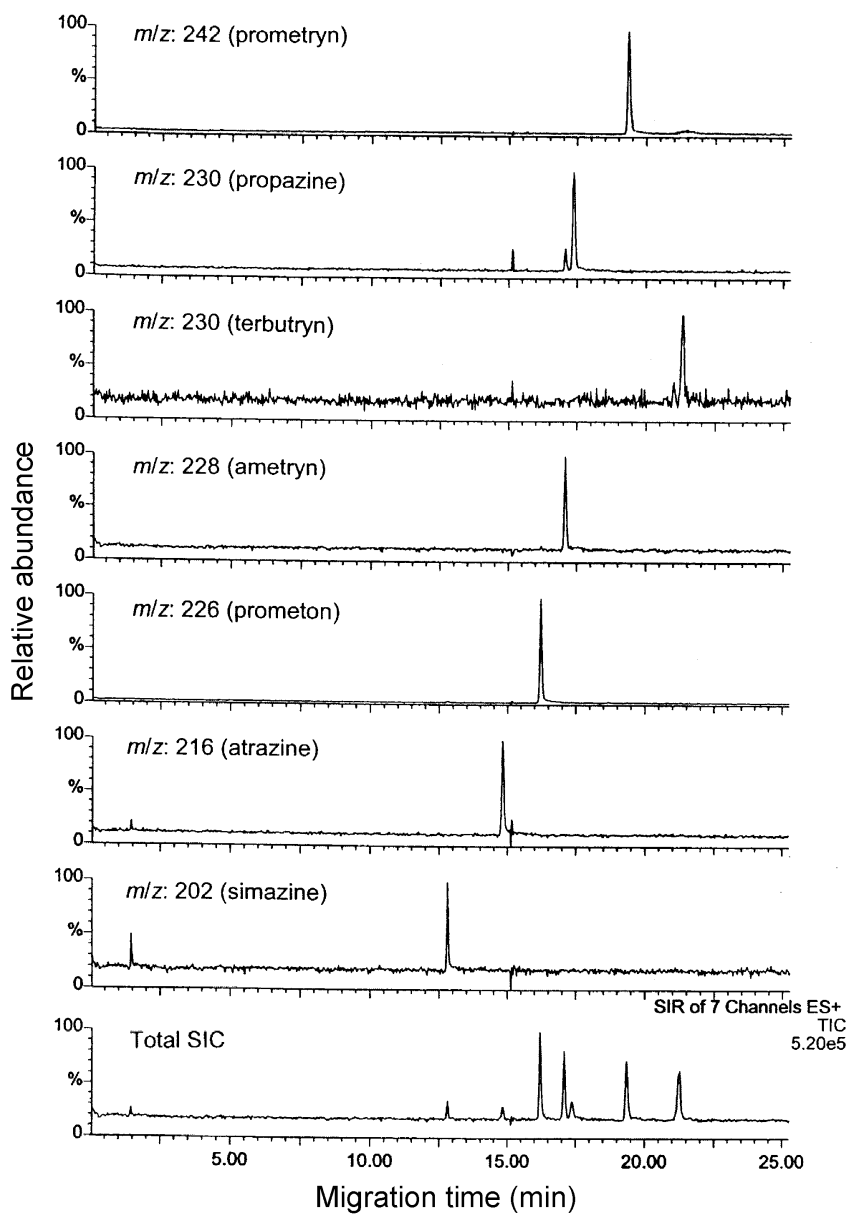

Figure 4. Reconstructed ion electropherograms of seven $s$-ritarine herbicides in MLKC-LSIMS using a positive ion mode. Conditions: capillary. $120 \mathrm{~cm}$ total length. $50 \mu \mathrm{m}$ I.D.. and $365 \mu \mathrm{m}$ O.D: sheath liquid. methanol/wateriformic acid (59:49:1 v/v/v). I0 $/ 4 \mathrm{Lmin}$; voluage $\cdot 30 \mathrm{kV}$ at the inlet reserwoir and $\cdot 4 \mathrm{kV}$ al the electrospray nesdle: selected fon monitoring at mi 202 (simazine). 216 (atrazinc). 226 (prometon). 228 (ametryn). 230 (propazinc). 242 (prometrys). and 230 (terbutryn). Sample concentration: $250 \mathrm{ppb}$ at tolal SIC. Other conditions were the same as in ligure I.

ESI performance. The highest sensitivity with good stability was observed at about $2 \mathrm{~mm}$ outside the stainless sheath tube. The sheath liquid containing $50 \%$ methanol $/ 49 \%$ water $/ 1 \%$ formic acid was introduced to the electrospray probe at the cathodic end for the positive ESI. The optimum flow-rate was found to be $10 \mu \mathrm{L} / \mathrm{min}$ for a suitable ESI operation. The mass spectrometer was operated at the SIM mode in MEKC-ESIMS analysis. Compared with the full scan mode, the sensitivity of the SIM mode is much higher because it removes the background ions for low level analyte. Even though the migration times of two analytes were very close in MEKC-UV detection (peaks 4 and 5 in Figure 1), we could monitor each analyte separately in MEKC-ESIMS (Figure 4). Thus, the SIM mode was chosen for mass spectrometer operation. Finally, electropherograms of MEKC-ESIMS and MEKC with UV detection were compared, but differences between two methods were hardly found. Figure 4 shows the single-ion electropherograms obtained from the MEKC separation and ESIMS detection
Table 2. Llution order and eapacity factor for seven s-triazins herbicides in UV and ESIMS detection

\begin{tabular}{lcc}
\hline Analyte Peak & $\begin{array}{c}\text { I:lution Order } \\
\text { (1) }: \text { FSIMS) }\end{array}$ & $\begin{array}{c}\text { Capacily Factor } \\
\text { (IV) }\end{array}$ \\
\hline Simazine & $1: 1$ & 0.43 \\
Aatrazine & $2: 2$ & 0.66 \\
Prometon & $3: 3$ & 0.77 \\
Aametryn & $4: 4$ & 0.88 \\
Propazine & $5: 5$ & 0.91 \\
Prometryn & $6: 6$ & 1.08 \\
Terbutryn & $7: 7$ & 1.25 \\
\hline
\end{tabular}

Capacity factor $\left.\left.k^{\prime}=\left(\mathrm{t}_{1}-\mathrm{t}_{1}\right):\left[\mathrm{t}_{0}:\left(1-\mathrm{t}_{1}\right) \mathrm{t}_{\mathrm{mc}}\right)\right\}\right]$ where $\mathrm{t}_{\mathrm{i},}$ and $\mathrm{t}_{\mathrm{mc}}$ are the migration times of the solute (methanol) which do not interact with the micelle and the solute (sudars III) which fully interacts with micelle. respectively.

for seven $s$-triazine herbicides. Each peak was assigned to seven $s$-triazines based on the molecular weight (Table I). The elution order and the capacity factor of triazines are summarized in Table 2 for the comparison of both detections of UV and ESIMS. In the MEKC-ESIMS, the elution order's were the same as those in the MEKC-UV detection (Table 2). In comparison to MEKC-UV studies, the migration times of seven s-triazines were longer under the same run buffer. For example, the migration times of simazine in MEKC-UV and MEKC-ESL/MS were 7.48 and $12.80 \mathrm{~min}$, respectively. The increase in the migration time of triazine herbicides in MEKC-ESIMS was attributed only to the reducing electric field strength.

The separation efficiency, represented by the number of theoretical plates, $N$, was calculated from the peak halfwidth for each triazine. The range of efficiencies for triazines in MEKC-UV and MEKC-ESIMS were 55 000217000 and 99000-363000, respectively (Table 3). A little increase in separation efficiency of triazine herbicides was observed in MEKC-ESIMS. The mixing between the capillary eluent and the sheath liquid at the capillary tip results in the decrease of separation efficiency and resolution of analytes in MEKC-ESIMS..$^{20}$ However, the applied electric field with same pressure increased the separation

Iable 3. Comparison of the numbers of theoretical plates and delection limit for seven s-triazine herbicides in UV detection and LSIMS detection

\begin{tabular}{|c|c|c|}
\hline Triazines & $\begin{array}{c}\text { UV } \\
\left.\left(\mathrm{N}^{n /} / \mathrm{OI}\right)^{h}\right)\end{array}$ & $\begin{array}{c}\text { FSIMS } \\
\left(A^{3} /(,(O))^{b}\right)\end{array}$ \\
\hline Simavine & $55000 / 1.0$ & $36.3000 / 0.050$ \\
\hline Nuarine & $116000 / 1.0$ & $122000 / 0.050$ \\
\hline Prometor & $183000 / 0.5$ & 22700000.010 \\
\hline Amelry] & $217000 / 1.0$ & 25300000.013 \\
\hline Propavine & $187000 / 1.0$ & 9900000.050 \\
\hline Prometryin & $135000 / 0.5$ & $207000 / 0.014$ \\
\hline lerbutry & $172000 / 1.0$ & $138000 / 0.015$ \\
\hline
\end{tabular}

"The numbers of theoretical plates $\left(A=5.54\left(\mathrm{t}_{\mathrm{m}} / \mathrm{n} /: 2\right)^{2}\right.$ where $\mathrm{I}_{\mathrm{m}}$ is the migration lime of the analye and wi:s is the peak width at half-lieight. I. imit of detection $(\mu \mathrm{g} / \mathrm{ml}): S /=3$. 
efficiency in this MEKC-ESIMS system. Though an additional band-broadening phenomenon at the interface between the moving SDS phase and the nunning buffer further contributed to generally lower separation efficiency of seven s-triazines. the introduction of pressure at the applied field strength decreased the band-broadening phenomenon and the elution time. Above all. in the case of long capillary the applied voltage with pressure could faster elute the analytes than the applying only voltage without pressure (data not shown).

The detection limits of seven $s$-triazine herbicides were in the low ppm range in MEKC-UV (Table 3). These sensitivities are not adequate for the detection of many enrironmental samples without pre-treatment steps. The detection limits in MEKC-ESIMS were about 20-50 times lower than those in MEKC-UV. Recently, although various preconcentration steps prior to CE such as "cloud point extraction" "21 and/or "capillary isoelectric focusing" been developed for increasing the detection sensitivity. these techniques are still relatively time-consuming. However. the sensitivity of MEKC-ESIMS should be enough for direct detection of real samples present in environmental matrix without any pretreatments.

\section{Conclusions}

In this study the simultaneous determination of seven $s$ triazine herbicides by MEKC-ESIMS was presented. Information on the stnicture of $\mathrm{CE}$-separated triazine peaks could be determined from both of UV and MS data. even when the triazines were of the same charge and similar stnicture. The results showed that $s$-triazine herbicides were separated and analyzed within $12 \mathrm{~min}$ in UV detection and $23 \mathrm{~min}$ in ESIMS detection without any pretreatment steps. The MEKC-ESIMS detection showed 5 to 10 times higher sensitivity compared to the MEKC-UV detection. In addition. it did not need any pretreatment step. The CE-MS technique may prove to be a useful qualitative and quantitative tool for similar en irommental pollutants.
Acknowledgments. This work was supported by Ministry of Environment as "The Eco-technopia 21 project".

\section{References}

1. Terabe, S.; Otsuka, K: Ichikawa, K.: Tsuchiva, A.; Ando, T. Anal. Chem. 1984. 56. 111.

2. Baker. D. R. Capillon, Electrophoresis: A Wiley-Interscience Publication: New York. U. S. A.. 1995: p 58.

3. Foret, F.: Sustac. V.: Bocek. P. Electrophoresis 1990. 11.95.

4. Schmitt, P.; Garrison, A. W.: Freitag. D; Kettrup, A. J. Chontatogr: A 1996, 723. 169

5. Cai. J.: Rassi. Z. E. J. Chomatog: 1992. $608,31$.

6. Carabias-Martinez. R.: Rodriguez-Gonzalo. E.: Dominguez-Alvarez. J.: Hernandez-Mendez. J. J. Chromatogr A 2000. 869. 451.

7. Carabias-Martinez. R.: Rodriguez-Gonzalo. E.: DominguezAlvarez, J.: Hernandez-Mendez, J. Electrophoresis 2002, 23. 494.

8. Carabias-Martinez. R: Rodriguez-Gonzalo. E: DominguezAlvarez. J: Hernandez-Mendez. J. Anal Chem. 1997. 69, 437.

9. Snith. R. D.: Olivares. T. A.: Nguyen. N. T.: Udseth. H. R. Anal. Chent 1998.60 .426

10. Moseley. M. A.: Jorgensont. J. W.: Shabanowitz. T.: Hunt. D. F.: Tomer, K. B. J.Ant. Soc. Hass Spectrum 1992. 3. 289.

11. Pleasance, S.: Thibault. P.; Kelly. J. J. Chomatog: $1992,59,325$.

12. Moseley, M. A.: Deterding. L. J.: Tomer. K. B.; Jorgenson. J. W. Anal Chem 1991. 63. 109 .

13. Moseley. M. A.: Deterding. L. T.: Tomer. K. B.: Jorgenson1. I. W. J. Chrontatogr. 1990. 516.167.

14. Hopfgartner, G.; Wachs, T.: Bean, K:; Henion. J. Anal. Chent. 1993. 65,439

15. Jun. S.: Yoshihisa U.; Akihiro, K.: Ikuroshin. K. Anal Biochem. 1992. 207.1.

16. Baker. D. R. Capillary Electrophoresis: A Wiley-Interscience Publication: New York. U. S. A.. 1995: p 26.

17. Cohen. A. S.: Paulus, A.; Karger, B. L. Chrontatogrphia 1987, 24. 15.

18. Foret, F.: Bocek. P. In Adwances in Electophonsis; Chrambach. A.: Dunn. M. J.: Radola. B. J.. Eds.: VCH: Weinheim. 1989: p 273.

19. Matchett. W. H.: Winnik. W.: Brumley. W. C. J. Cap. Elec. 1996. 3. 199 .

20. Yang. L.: Harrata. A. K.: Lee, C. S. Anal Chem. 1997. 69. 1820.

21. Carabias-Martinez. R; Rodriguez-Gonzalo, E; DominguezAlvarez. J.: Hernandez-Mendez. J. Anat. Cham. 1999. 71. 2468.

22. Schmitt. Ph.: Poiger. T.: Simon. R.: Freitag. D.: Kettrup. A.: Garrison. A. W. Anal. Chent. 1997. 69.2559. 